\section{NOVA TELLVS}

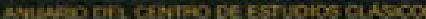
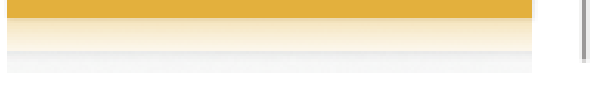

\section{Nova Tellus}

ISSN: 0185-3058

novatelu@servidor.unam.mx

Centro de Estudios Clásicos

México

Herrera Zapién, Tarsicio

Los poderosos Carmina Burana de Carl Orff. Estudio y traducción rítmica castellana

Nova Tellus, vol. 30, núm. 1, 2012, pp. 217-237

Centro de Estudios Clásicos

Distrito Federal, México

Disponible en: http://www.redalyc.org/articulo.oa?id=59128312015

- Cómo citar el artículo

Número completo

- Más información del artículo

Página de la revista en redalyc.org

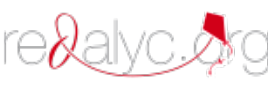

Sistema de Información Científica

Red de Revistas Científicas de América Latina, el Caribe, España y Portugal

Proyecto académico sin fines de lucro, desarrollado bajo la iniciativa de acceso abierto 


\title{
Los poderosos Carmina Burana de Carl Orff. Estudio y traducción rítmica castellana
}

\author{
Tarsicio HERRERA ZAPIÉN \\ Universidad Nacional Autónoma de México \\ tarherzap@yahoo.com.mx
}

\begin{abstract}
RESUMEN: Los Carmina Burana — ciclo de poemas anónimos encontrados en la abadía de Benediktbeuern, en Baviera- constituyen una típica colección de gozosos cantos de los goliardos medievales, frailes retirados de algunas abadías benedictinas. De esta colección, los humanistas J. A. Schmeller y M. Hoffmann formaron cinco grupos contrastantes de poesías: el triunfo de la fortuna, una escena de la primavera, unas danzas en el prado, una escena en la taberna y una conclusiva corte de amor. Carl Orff compuso con ellos una partitura que ha tenido por medio siglo un enorme éxito, tanto en forma de ballet como de coral sinfónico. Se traducen aquí rítmicamente todos los coros, que pueden también cantarse con precisión en español.
\end{abstract}

\section{The Powerful Carmina Burana by Carl Orff. Study and Rhythmic Spanish Translation}

ABstract: Carmina Burana, cycle of anonymous poems found in the Benediktbeuern Abbey of Bavaria, is a typical collection of cheerful songs by medieval Goliards, i.e, monks retired from benedictine abbeys. Based on this collection, the scholars J. A. Schmeller and Michel Hoffmann formed five contrasting sets of poems: the Triumph of Fortune, a Spring scene, dances in the meadow, a scene in the tavern and a conclusive court d'amour. Carl Orff composed for them a musical score that for half a century has had a huge success, both in form of ballet and of symphonic chorale. Here, all the choruses are given in rhythmical translation, so that they can be properly sung in Spanish.

PALABRAS ClaVE: Carl Orff, goliardos, poesía medieval, danza, latín.

KEYwords: Carl Orff, Goliards, medieval poetry, dance, Latin.

FECHA DE RECEPCIÓN: 11 de octubre de 2011.

FECHA DE ACEPTACIÓN: 27 de agosto de 2012. 



\title{
Los poderosos Carmina Burana de Carl Orff. Estudio y traducción rítmica castellana
}

\author{
Tarsicio HERRERA ZAPIÉN
}

\section{Introducción}

El origen de los Carmina Burana

Los Carmina Burana ${ }^{1}$ son un caso excepcional en la historia de la música. Se trata de 22 poesías líricas en latín familiar, salvo dos y media en alto alemán, y otra en latín entreverado de provenzal. Muchas de ellas son anónimas, y fueron encontradas durante el siglo XIX en el monasterio de Benediktbeuern por el investigador J. A. Schmeller. Contaban ya incluso con algunas melodías gregorianizantes que casi a nadie interesaban, cuando se apoderó de ellas el ingenio de Carl Orff en 1937.

Orff decidió seleccionar, con ayuda del musicólogo Michael Hoffmann, las 22 poesías mencionadas, y ponerles una música que cantaran masas de estudiantes y obreros y centenares de grupos infantiles. Para ello creó la partitura profana más rítmica y pegajosa que pueda imaginarse, pues llega a lo primitivo y salvaje, basada más en el ritmo y en la recitación que en la melodía, y construida a base de cuartas y quintas robustamente medievales. Usó también los modos eclesiales, pero sólo a causa de la distensión lírica inherente a las modalidades gregorianas; y las situó después de cada uno de los doce grandes coros que han inmortalizado a su cantata Carmina Burana.

El ciclo poético que dio origen a este monumento musical pertenece a la baja Edad Media, hacia el siglo XIII, cuando la lengua imperial había adquirido una enorme fluidez rítmica y fonética.

El éxito de esta colección fue fulminante. El terrible Führer adoptó algunos de esos coros como himnos del nazismo, si bien otros opinan que los propios coros de la "Fortuna" (Fortunae rota volvitur, "la rue-

${ }^{1}$ Carmina Burana o Poemas de Bura. Bura es una forma latina abreviada de Benediktbeuern, un municipio de Baviera, Alemania [N. del E.]. 
da de la Fortuna da vueltas") ya pronosticaban la derrota del líder. Al caer Hitler, la gloria musical de Carl Orff quedó en entredicho. Pero un cuarto de siglo después de aquel 1945 en que Europa fue liberada, ya el olvido social reaccionaba ante el genocidio, y la memoria histórica comenzó a rescatar la belleza pura de los soberbios coros de Orff.

Hoy día, los Carmina Burana se representan en todas las formas posibles: en conciertos sinfónicos, en temporadas de ópera, en programas de ballet, en recitales de coros. ${ }^{2}$ Incluso fueron usados hasta en arreglos de rock por los Doors. En 2003, el grupo Diez pianos en concierto incluyó el coro "O Fortuna" en su repertorio instrumental.

\section{El repertorio de Orff}

Tras el éxito del latín goliárdico de los Carmina Burana (1937), Orff completó su tríptico Trionfi con el latín clásico de su "concierto escénico" Catulli carmina (1948) y con el de la cantata II Trionfo di Afrodite (1953). En la misma línea clasicista, Orff se abocó a musicalizar tragedias griegas: compuso una Antígona (de 1949) en alemán; un Oedipus (de 1959) también en alemán, y un Prometheus (en 1966), en griego clásico. Por lo demás, Orff trató también temas sacros, desde un dulce Cuento de Navidad, en alemán, hasta una Comoedia de Christi resurrectione (1957) y una desgarradora De temporum fine comoedia (de 1973), ambas en latín bíblico.

¿Quién se iba a imaginar tal éxito en una obra como Carmina Burana, derivada, en un aspecto, desde el ácido acento de Las bodas de Stravinsky (1923) y, en el otro, desde la sutileza de la salmodia gregoriana medieval? El secreto es la fogosa orquestación arriba anotada. Más aún, esos espléndidos coros orgiásticos son favoritos para anuncios comerciales que exaltan la "fortuna" que hace falta para poder comprar ciertos autos de lujo.

Hagamos nuestra esa fortuna musical: es un triunfo del ritmo, pero también de la lengua latina, que han corrido parejas durante siglos en la historia de la música.

${ }^{2}$ A esta línea pertenece la grabación en CD: Carl Orff, Carmina Burana, 2001. Orquesta de Cámara de la Escuela Nacional Preparatoria. Director Luis Samuel Saloma. Coros de los nueve planteles de la ENP. Coordinación: María Teresa Gutiérrez. Grabación: ENP. Sala Nazahualcóyotl, en vivo. 


\section{Canteras para un pórtico}

Otras obras ganan aplausos, Carmina Burana arranca al público no sólo ovaciones, sino hasta gritos de júbilo. Entre las partituras más aclamadas se cuenta esta cantata sinfónica al lado de la desgarradora Sinfonía de Salmos de Stravinsky y de los Requiem polarmente opuestos entre sí de Verdi y de Fauré. El texto latino, relevante en todas estas obras, no les quita claridad, y sí les añade la resonancia de una tradición de muchos siglos.

\section{La cantata de Orff es mina de antítesis}

Mientras las óperas de Verdi y Puccini gustan por su texto actual, los cantos buranos deleitan por el sabroso arcaísmo de sus estrofas redactadas en el siglo XIII por clérigos "eruditos" como Hugo de Orleans:

\section{O Fortuna, velut luna, statu variabilis.}

Pero el latín de esos poemas no es la hermética lengua de los aforismos de Horacio y de Cicerón. En los cantos compuestos en latín vivo y seleccionados por el citado musicólogo y humanista Michael Hoffmann a partir de la colección de J. A. Schmeller, todo es claridad, ritmo, rima regocijada:

Bibit velox, bibit piger
bibit albus, bibit niger.

Los clásicos romanos, por otra parte, medían sus versos por duración silábica, o sea cuantidad, y casi nunca rimaban. En cambio los poemas de Beuren, como los himnos de su época, avanzaban hacia las métricas modernas al abundar en rimas felices y en versos de medidas constantes.

¿Cómo logra Carl Orff la grandeza por medio de la plena sencillez expresiva?

Comienza por construir con bloques de piedra noble melodías de llana claridad. Las estructuras luego siguen en vastas galerías de ritmos obstinados. Y estas unidades mayores las dosifica en claroscuros de impacto graduado entre lo etéreo y lo arrollador. Ante una vasta fachada 
sugerida por la orquesta en pleno, coloca el autor a los coros mixtos, que comienzan desplegando, como pórticos, dos alucinantes coros de la Fortuna que gobierna el mundo. Junto a ellos, el barítono pinta luego, sin prisas, el fresco del "Sol sutil", en medio de la escena de la primavera. Después de desplegar los senderos de una colorida danza "En el prado", Orff nos introduce al salón del palacio donde el tenor parece una hoguera que chisporrotea las tres agudísimas estrofas del "Cisne asado". Recorremos después ese gran salón en el orgiástico "Coro universal de bebedores", que caldea hasta los cimientos del teatro.

Entonces sale a escena, que es como salir a un jardín, la brisa fresca de la soprano seguida por el coro de niños, para ejecutar junto al barítono la "Corte de amores". Es el momento apto para que el barítono, ante coros y orquesta, entone una serenata de acentos medievales a la soprano que sueña en su alto aposento:

La muchacha sin galán / de placer carecerá.

Luego de los coloquios del barítono, asomará ella bajo su ajimez para entonar:

Llegó la niña / con roja túnica;

si alguno tócala, / tiembla la túnica.

Nuevos despliegues del galán y del coro nos pasean por el jardín, hasta que finalmente nos introduce a la alcoba, donde la soprano medita en voz baja:

Van en mi mente oscilando

dos pesos contrarios:

mi amor lascivo y mi recato.

El palacio sinfónico de los cantos de Beuren tiene tres planos conclusivos. Inicialmente, un recorrido por patios y jardines en el coro múltiple: "El tiempo es gozoso, oh vírgenes". Luego, la sala del trono de Venus en el coral poderoso: “iSalve, la hermosísima!". Y por fin, el retorno a la fachada "O Fortuna, velut luna", de múltiples pórticos y ojivas.

Cerrado el ciclo de la diosa Fortuna, comienza el cataclismo de vítores y ovaciones del público. Así sucedió en Frankfurt durante el estreno 
en 1937. Así viene sucediendo cada vez que reaparece esta obra en cualquier teatro y en cualquier país del mundo.

El ciclo poético que ha originado este monumento musical era merecedor de una versión que se ciñera a los variados ritmos y rimas de su texto latino. He aquí nuestra versión rítmica. Además de poder auxiliar la audición sinfónica, tratamos de que se pueda imponer por su propio respeto a la majestad verbal del texto latino, con su belleza polirrítmica y multirrimada.

\section{CARMINA BURANA}

Cantiones profanae cantoribus et choris cantatae, comitantibus instrumentis atque imaginibus magicis.

\section{SCAENA PRIMA}

FORTUNA, IMPERATRIX

MUNDI

(Chorus)

1. O Fortuna, velut luna statu variabilis, semper crescis aut decrescis; vita detestabilis

nunc obdurat et tunc curat ludo, mentis aciem egestatem potestatem dissolvit ut glaciem.

Sors immanis et inanis, rota tu volubilis status malus, vana salus, semper dissolubilis,

obumbrata et velata mihi quoque niteris;
Canciones profanas para solistas y coros acompañados de instrumentos e imágenes mágicas (proyecciones).

\section{ESCENA PRIMERA}

\section{LA FORTUNA, EMPERATRIZ \\ DEL MUNDO}

(Coro)

1. ¡Oh, Fortuna, como luna de estado variable: siempre creces o decreces!; la vida execrable

ora ataca ora aplaca por juego, a la mente la pobreza, la riqueza cual hielo disuelve.

Suerte ingente, suerte inerte, tú, rueda voluble, pobre etapa, salud falsa, y siempre soluble,

ocultada

y velada vas siempre asediándome; 
nunc per ludum

dorsum nudum

fero tui sceleris.

Sors salutis

et virtutis

mihi nunc contraria,

est effectus

et defectus

semper in angaria.

Hac in hora,

sine mora

corde pulsum tangite,

quod per sortem,

sternit fortem,

mecum omnes plangite!

\section{VULNERA}

(Chorus)

2. Fortunae plango vulnera stillantibus ocellis, quod sua mihi munera subtrahit rebellis.

Verum est, quod legitur fronte capillata, sed plerumque sequitur occasio calvata.

In Fortunae solio sederam elatus prosperitatis vario flore coronatus.

Quisquis tamen florui felix et beatus, nunc a summo corrui gloria privatus

Fortunae rota volvitur: descendo minoratus; alter in altum tollitur, nimis exaltatus

rex sedet in vertice: caveat ruinam! nam sub axe legimus Hecubam reginam. hoy la espalda

desnudada

llevo por tus crímenes.

En la salud y en la virtud la suerte hoy contraria me es, tiene aciertos y defectos siempre quien servirla ves.

En esta hora sin demora al pecho herido acudid, pues la suerte postra al fuerte. ¡Lloren todos junto a mí!

\section{LAS LLAGAS}

(Coro)

2. De Fortuna las llagas lloro a ojos destilantes, porque ella a mí sus dádivas substrae desafiante.

Está, sí, cual léese, con frente poblada, pero a veces síguela Una ocasión calva.

Yo con la fortuna me sentí exaltado con flor de riqueza varia coronado.

Mas, aunque he lucido feliz y halagado, de lo alto he caído de gloria privado

De Azar la rueda vuélvese y desciendo amenguado; otro hasta lo alto elévase; por demás exaltado un rey va en la cúspide: ¡tema por su ruina! Pues so el eje a Hécuba vemos, siendo reina. 
SCAENA SECUNDA

PRIMO VERE

(Semichorus)

3. Veris laeta facies mundo propinatur, hiemalis acies victa jam fugatur.

In vestitu vario

Flora principatur, nemorum dulcisono quae cantu celebratur.

Florae fusus gremio Phoebus novo more risum dat, hoc vario jam stipatur flore.

Zephyrus nectareo spirans in odore; certatim pro bravio curramus in amore.

Cytarizat cantico dulcis Philomena flore ridens vario prata jam serena;

salit coetus avium silvae per amoena, chorus promit virginum jam gaudia millena.

\section{SOL SUBTILIS}

(Baytonus)

4. Omnia sol temperat purus et subtilis, novo mundo reserat faciem Aprilis;

ad amorem properat animus herilis, et jucundis imperat deus puerilis

Rerum tanta novitas in solemni vere
ESCENA SEGUNDA

EN LA PRIMAVERA

(Medio coro)

3. Paz primaveral al mundo se ostenta; la fuerza invernal vencida se aleja.

Con vario vestido Flora es exaltada, con canto dulcísono del bosque es honrada.

En brazos de Flora Febo en nuevo modo ríe, al ver que en flores queda oculto todo.

Céfiro ya sopla con nectáreo olor; a porfía el premio busquemos de amor.

Arrulla en su cántico dulce Filomena, y ríe con flores campiña serena;

bandada de aves salta en selva amena; y un coro de vírgenes de gozos [se] llena.

\section{EL SOL SUTIL}

4. (Barítono)

El sol todo a templar va sereno y sutil, a orbe nuevo muestra ya su semblante Abril;

se preocupa por amar la fuerza viril, y gozosa órdenes da deidad infantil.

Qué agradable novedad en la estación nueva. 
et veris auctoritas

jubet nos gaudere;

vias praebet solitas,

et in tuo vere

fides est et probitas

tuum retinere

Ama me fideliter,

fidem meam nota:

de corde totaliter

et ex mente tota.

sum presentialiter

absens in remota;

quisquis amat taliter,

volvitur in rota.

\section{VER GRATUM}

(Chorus)

5. Ecce gratum

et optatum

ver reducit gaudia!

Purpuratum

floret pratum;

Sol serenat omnia.

Jam jam cedant tristia!

Aestas redit,

nunc recedit

Hiemis saevitia.

Jam liquescit

et decrescit

grando, nix, et caetera;

bruma fugit

et jam sugit

ver aestatis ubera.

Illi mens est misera

qui nec vivit

nec lascivit

sub aestatis dextera.

Gloriantur

et laetantur

in melle dulcedinis,
Su inefable autoridad

a gozar nos lleva;

nos da un camino habitual

y en tu primavera

es lealtad y probidad

que tu bien retengas.

Ámame fielmente

mi lealtad anota:

muy íntimamente

con la mente toda

aquí estoy realmente

en parte remota;

al que este amor siente

la rueda lo rota

\section{LA GRATA PRIMAVERA}

(Coro)

5. Ved que, grata

y esperada,

primavera gozos dio.

Purpurado

luce el prado;

el sol todo serenó.

¡Huya cuanto es tétrico!

Llega estío,

huye el frío

del invierno destructor.

Ya licuece,

ya decrece

nieve, granizo y demás;

brumas ¡fuera!,

Primavera

chupa ya la ubre estival.

Tiene mente mísera

quien no goza

ni retoza

del estío a la señal.

Se solazan,

bien la pasan

con la miel de este dulzor, 
qui conantur, ut utantur

praemia Cupidinis.

Simus jussu Cypridis

gloriantes

et laetantes

pares esse Paridis.

SCAENA TERTIA

AUF DEM ANGER

\section{Tanz}

(Chorus)

7. Floret silva nobilis

floribus et foliis.

(Semichorus)

-Ubi est antiquus

meus amicus?

- Hinc equitavit, equitavit

eia, quis me amabit?

\section{(Chorus)}

Floret silva undique,

nah mime gesellen ist mir we.

(Semichorus)

Gruonet der walt allenthalben, wa ist mein geselle alse lange?

Der ist geriten hinnen, o wi, wer sol mich minnen?

(Semichorus)

8. Chramer, gip die varwe mir, die min wengel roete, damit ich die jungen man an ir dank minnenliebe noete.

(Naenia)

Cerne me, juvenis, te sine ut delectem!

Minnet, tugentliche man, Minnecliche frouwen: minne tuot iu hoch gemuot quienes busquen

el disfrute

del premio del niño amor.

De Venus por órdenes

retocemos

y gocemos

igual que Paris gozó.

ESCENA TERCERA

EN EL PRADO

6. Danza

(Coro)

7. Triunfa el bosque noble con hojas y flores.

(Medio coro)

— ¿Dónde está mi antiguo, mi caro amigo?

-Fue a cabalgar, cabalgar... ¡Ay! ¿Y quién me va amar?

(Coro)

Florece el bosque doquiera.

¡Que mi amado aquí estuviera!

(Medio coro)

Si el bosque está reverdecido, ¿por qué mi amado está tan lejos?

De mi huyó cabalgando, ¿quién me seguirá amando?

(Medio coro)

8. Dadme, tendero, el color que enciende mi cara, por que pueda yo a los jóvenes atrapar y guiarlos al amor.

(Estribillo)

¡Mírame a mí, joven viril!

¡Déjame agradarte!

¡Amen los hombres ardientes

y amables mujeres!

Amor hace a los valientes 
unde lat iuch in hohen

eren schouwen.

(Naenia)

Seht mich an

Jungen man!

Lat mich iu gevallen!

Wol dir, werlt, daz du bist

also freuden riche!

ich wil dir sin undertan

durch din liebe immer sicherliche.

(Naenia)

Seht mieh an

Jungen man!

Lat mich iu gevallen!

\section{REIE}

(Chorus)

Swatz hie gat umbe, daz sint alles megede, die wellent an man allen disen sumer gan!

(Semichorus)

Chume, chum, geselle min, ih enbite harte din.

Suzer rosenvarwer munt, chum und mache mich gesunt.

(Chorus)

Swaz hie gat umbe, daz sint alles megede, die wellent an man allen disen sumer gan!

(Chorus)

10. Were diu werlt alle min von dem mere unze an den Rin, des wolt ih mih darben, daz diu chünegin von Engellant lege an minen armen.

SCAENA QUARTA

IN TABERNA

(Barytonus)

11. Aestuans interius $\mathrm{y}$ los hace dignos

de altos honores.

(Estribillo)

¡Mírame a mí, joven viril!

¡Déjame agradarte!

¡Mundo: sé tú bienvenido rico en alegrías!

Te estaré sometido,

fiel a tus amores cada día.

(Estribillo)

¡Mírame a mí, joven viril!

¡Déjame agradarte!

\section{DANZA CIRCULAR}

(Coro)

¡Allá van girando, todas ellas vírgenes queriendo el verano todo estar con jóvenes!

(Medio coro)

Ven, amada, ven acá, te suplico, o me haces mal. Boca rosa, dulce miel, ven y dame todo el bien.

(Coro)

¡Allá van girando todas ellas vírgenes, queriendo el verano todo estar con jóvenes!

(Coro)

10. Si el mundo mío fuera sólo con que el Rín pasara, yo aquí hambres sufriera si a la reina de Inglaterra a mí la estrechara.

ESCENA CUARTA

EN LA TABERNA

(Barítono)

11. Ardiendo en lo íntimo 
ira vehementi

in amaritudine

loquor meae menti:

factus de materia,

cinis elementi,

similis sum folio,

de quo ludunt venti.

Cum sit enim proprium

viro sapienti

supra petram ponere

sedem fundamenti,

stultus ego comparor

fluvio labenti,

sub eodem tramite

numquam permanenti.

Feror ego veluti

sine nauta navis,

ut per vias aeris

vaga fertur avis;

non me tenent vincula,

non me tenet clavis,

quaero mihi similes

et adjungor pravis.

Mihi cordis gravitas

res videtur gravis;

jocus est amabilis

dulciorque favis.

Quidquid Venus imperat,

labor est suavis,

quae numquam in cordibus

habitat ignavis.

Via lata gradior more juventutis, implicor et vitiis immemor virtutis.

Voluptatis avidus, magis quam salutis, mortuus in anima, curam gero cutis.

\section{CICNUS USTUS CANTAT}

(Tenor)

12. Olim lacus colueram, olim pulcher exstiteram dum cicnus ego fueram. con ira vehemente, presa de amargura

hablo con mi mente: hecho de materia, -cinéreo elementosoy como una hoja con que juega el viento.

Pues como es lo propio del varón prudente que sobre una roca el cimiento asiente, tonto, me comparo a un río fluyente, que en un mismo tramo nunca permanece.

Soy llevado como lo es sin patrón la nave, como entre los vientos incierta va el ave; no me fijan vínculos, no me fija llave, me uno a los perversos, que son mis iguales.

A mí la cordura parece algo grave; el juego más dulce que el panal me sabe. Cuanto Venus mándame es trabajo suave, que ella nunca habita en cobarde enclave.

Voy por la ancha vía cual la juventud; me enredo en los vicios, ciego a la virtud. De placeres ávido, más que de salud, muerto en el espíritu, busco laxitud.

\section{EL CISNE ASADO CANTA}

\section{(Tenor)}

12. Yo, antes, lagos surcaba, bello antes destacaba mientras cual cisne ondeaba. 
(Chorus virilis. Naenia)

Miser, miser!

Modo niger

et ustus fortiter!

(Tenor)

Girat, regirat garcifer;

me rogus urit fortiter;

propinat me nunc dapifer

(Naenia)

Miser, miser!

Modo niger

et ustus fortiter!

(Tenor)

Nunc in scutella jaceo

et volitare nequeo,

dentes frementes video.

(Naenia)

Miser, miser!

Modo niger

et ustus fortiter!

\section{ABBAS CUCANIENSIS}

(Barytonus)

13. Ego sum Abbas Cucaniensis et consilium meum est cum bibulis, et in secta Decii voluntas mea est, et qui mane me quaesierit in taberna, post vesperem nudus egredietur, et sic denudatus veste clamabit:

(Barytonus et chorus virilis)

Wafna, wafna!

Quid fecisti, sors turpissima?

Nostrae vitae gaudia

abstulisti omnia!

14. (Potatorum chorus)

In taberna quando sumus, non curamus quid sit humus, sed ad ludum properamus cui semper insudamus.

Quid agatur in taberna ubi nummus est pincerna,
(Coro varonil. Estribillo)

¡Mísero, mísero!

¡Hoy mortífero

y el más pestífero!

(Tenor)

Gira y gira la garra,

el fuego me desgarra;

el cocinero embarra.

(Estribillo)

¡Mísero, mísero!

¡Hoy mortífero

y el más pestífero!

(Tenor)

En el cazo hoy me tienden

y volar no me sienten,

los dientes ya me muerden.

(Estribillo)

¡Mísero, mísero!

El más tétrico

Y el más pestífero!

\section{EL ABAD DE LA CUCAÑA}

(Barítono)

13. Yo soy el abad de la Cucaña

y mi deliberación es con los bebedores,

y en la escuela de Decio está mi voluntad,

y quien temprano me busque en la taberna,

al atardecer desnudo saldrá

y así despojado de su ropa clamará:

(Barítono y coro viril)

¡Bruto, bruto!

¿Qué hiciste, suerte infame?

¡Nos quitaste todos

del vivir los gozos!

(Coro de bebedores)

$\mathrm{Si}$ a la taberna acudimos, hacia el suelo nunca vimos, sino al juego nos lanzamos por el cual siempre sudamos.

Qué en el mesón nos divierta, donde abre el oro la puerta, 
hoc est opus ut quaeratur; si quid loquar, audiatur.

Quidam ludunt, quidam bibunt, quidam indiscrete vivunt.

Sed in ludo qui morantur. ex his quidam denudantur.

Quidam ibi vestiuntur, quidam saccis induuntur. Ibi nullus timet mortem, sed pro Baccho mittunt sortem.

Primo pro nummata vini, ex hac bibunt libertini: semel bibunt pro captivis, post haec bibunt ter pro vivis,

quater pro christianis cunctis, quinquies pro fidelius defunctis, sexies pro sororibus vanis, septies pro militibus silvanis.

Octies pro fratribus perversis, nonies pro monachis dispersis, decies pro navigantibus, undecies pro discordantibus, duodecies pro penitentibus, tredecies por iter agentibus. Tam pro papa quam pro rege bibunt omnes sine lege.

Bibit hera, bibit herus, bibit miles, bibit clerus, bibit ille, bibit illa, bibit servus cum ancilla,

bibit velox, bibit piger, bibit albus, bibit niger, bibit constans, bibit vagus, bibit rudis, bibit magus.

Bibit pauper et aegrotus, bibit exul et ignotus, bibit puer, bibit canus, bibit praesul et decanus,

bibit soror, bibit frater, bibit anus, bibit mater, hace bien quien lo investiga y que escucha qué yo diga.

Unos juegan, otros beben, otros, de ambos modos viven mas si en juego se han tardado, se han visto unos desnudados.

Unos allí son vestidos, otros, de sacos ceñidos. Nadie allí teme a la muerte, mas por Baco echa la suerte.

Primero por quien da el vino bebe el libre o el libertino: una vez por los cautivos y tres después por los vivos, cuatro por los buenos juntos, cinco por los fieles ya difuntos. seis por las hermanas desleales, siete por los guardias forestales,

Ocho por los hermanos perversos, nueve por los frailes dispersos, diez veces por navegantes, once por los litigantes,

doce por los penitentes, trece por los caminantes. Por el papa y por el rey todos beben sin más ley.

Beben amada y amado, bebe el clero y el soldado, bebe él y bebe ella, bebe el siervo y la doncella,

bebe el veloz, bebe el tardo, bebe el blanco, bebe el pardo, bebe el quieto, bebe el vago, bebe el rudo y bebe el mago.

Bebe el pobre y el lisiado, el extraño, el desterrado, bebe el niño, bebe el cano, bebe el noble y el decano, bebe el hermano y la hermana, bebe la madre y la anciana, 
bibit ista, bibit ille,

bibunt centum, bibunt mille.

Parum sexcentae nummatae durant cum immoderate bibunt omnes sine meta. Quamvis bibant mente laeta,

sic nos rodunt omnes gentes et sic erimus egentes.

Qui nos rodunt, confundantur et cum justis non scribantur.

\section{SCAENA QUINTA}

COUR D' AMOURS

(Pueri)

15. Amor volat undique, captus est libidine.

Juvenes, juvenculae

conjunguntur merito.

(Soprano)

Siqua sine socio, caret omni gaudio; tenet noctis infima sub intimo,

cordis in custodia.

(Pueri)

Fit res amarissima!

\section{COLLOQUIA}

(Barytonus)

16. Dies, nox et omnia mihi sunt contraria virginum colloquia

me fay planszer, oy suvenz suspirer, plus me fay temer.

O sodales, ludite, vos qui scitis dicite.

Mihi moesto parcite.

Grand ey dolur. attamen consulite per voster honur. bebe aquélla, bebe aquél, beben cien y mil con él.

Poco seiscientos ducados duran, cuando desbocados beben todos sin reposo. Aunque ellos beben gozosos, nos roen todas las gentes y nos harán indigentes. Quien nos roe, confundido sea, y no a justos unido.

\section{ESCENA QUINTA} CORTE DE AMORES

\section{(Niños)}

15. El amor vuela doquier, prendido por el placer.

Donceles y vírgenes

en su derecho únense.

(Soprano)

La muchacha sin galán de placer carecerá; tendrá en la noche ínfima en lo íntimo del pecho custodia.

(Niños)

¡Qué cosa amarguísima!

\section{LOS COLOQUIOS}

(Barítono)

16. Día, noche y todo para mí es gravoso; virginal coloquio

me causa placer, a menudo suspiré, pues me hace temer.

Compañeros, gócense; los que saben, díganlo. Triste estoy, perdónenme.

Tengo gran dolor. Empero, precávanse por su propio honor. 
Tua pulchra facies, me fay planszer millies. pectus habet glacies.

A remender, statim vivus fierem per un beser.

\section{RUFA TUNICA}

(Soprano)

17. Stetit puella

rufa tunica;

si quis eam tetigit, tunica crepuit.

Eja!

Stetit puella

tamquam rosula;

facies splenduit.

os ejus floruit.

Eja!

\section{SUSPIRIA}

(Barytonus et chorus)

18. Circa mea pectora multa sunt suspiria de tua pulchritudine quae me laedunt misere.

Manda iam,

Manda iam,

Mea delicia

abest clam.

Tui lucent oculi

sicut solis radii;

sicut splendor fulguris

lucem donat tenebris.

Manda iam,

manda iam.

Mea delicia

abest clam.

Vellet deus, vellent dii quod mente proposui: ut ejus virginea reserassem vincula.
Tu rostro es muy bello, en él me deleito, y en tu pecho hay hielo.

Al recordar, vivo al punto haríame: por tu besar.

\section{LA TÚNICA ROJA}

\section{(Soprano)}

17. Llegó la niña con roja túnica; si alguno tócala, tiembla la túnica ¡Ea!

Llegó la niña como una rosa; su faz espléndida, florida boca. ¡Ea!

\section{SUSPIROS}

(Barítono y coro) 18. En tono a mi pecho hay muchos suspiros por tus mil bellezas que me hieren mísero.

Manda ya, Manda ya, mi galán aún no está

Tus ojuelos fulgen del sol como rayos; tal, luz de relámpago la sombra ha inundado.

Manda ya,

Manda ya;

mi delicia

aún no está.

Quiera Dios, quieran los dioses lo que en mente decidí: que sus lazos virginales sean disueltos por mí. 
Manda iam,

Manda iam,

Mea delicia

abest clam.

\section{AMORES}

(Sex viri)

19. Si puer cum puellula moraretur in cellula,

felix conjunctio!

Amore subcrescente, pariter e medio propulso procul taedio, fit ludus ineffabilis membris, lacertis, labiis.

(Duplex chorus)

20. Veni, veni, venias, ne me mori facias;

hirca, hirce, nazaza, trillirivos...

Pulchra tibi facies, oculorum acies, capillorum series:

o quam clara species!

Rosa rubicundior, lilio candidior, omnibus formosior, semper in te glorior!

\section{FLUCTUATIONES}

(Soprano. Sedate)

21. In trutina mentis dubia fluctuant contraria:

lascivus amor

et pudicitia.

Sed eligo quod video, collum jugo prebeo; ad jugum tamen suave transeo.

NOVUS AMOR

(Chorus)

22. Tempus est jucundum,
Manda ya,

Manda ya:

mi delicia

aún no está.

\section{LOS AMORES}

(Seis varones)

19. Si el chico y la chiquilla moran en la celdilla, ¡qué feliz conjunción!

Cuando el amor se agranda, doblemente de en medio se echa lejos el tedio, se hace inefable el juego con brazos, labios, miembros.

(Doble coro)

20. Vente, vente, ven aquí, que sin ti me harás morir; chiva, chivo, aléjense, triple arroyo...

Es pulcro tu rostro, la fuerza en tus ojos, tu rubia guedeja: ¡qué clara belleza!

Más roja que rosa, más blanca que lirio, más que nadie hermosa, ¡en ti me glorío!

\section{TITUBEOS}

(Soprano. Pausadamente)

21. Van en mi mente oscilando dos pesos contrarios:

mi amor lascivo

y mi recato.

Mas tomo lo que veo, pongo al yugo el cuello; y es yugo suave al que me ofrezco.

\section{EL AMOR NUEVO}

(Coro)

22. El tiempo es gozoso, 
o virgines!

Modo congaudete

vos, juvenes!

(Barytonus)

$\mathrm{O}, \mathrm{o}, \mathrm{o}$,

totus floreo!

Jam amore virginali

totus ardeo.

Novus, novus, novus amor est, quo pereo.

(Feminarum Chorus)

Mea me confortat promissio,

mea me deportat

negatio.

(Soprani et pueri)

$\mathrm{O}, \mathrm{o}, \mathrm{o}$,

totus floreo!

Jam amore virginali

totus ardeo.

Novus, novus, novus amor

est, quo pereo.

(Virilis Chorus)

Tempore brumali

vir patiens;

animo vernali

lasciviens.

(Barytonus)

$\mathrm{O}, \mathrm{o}, \mathrm{o}$,

Totus floreo!

Jam amore virginali

totus ardeo.

Novus, novus, novus amor

est, quo pereo.

(Feminarum chorus)

Mea mecum ludit

Virginitas,

mea me detrudit

simplicitas.

(Soprano et pueri)

$\mathrm{O}, \mathrm{o}, \mathrm{o} .$. ¡oh vírgenes!

Ahora regocíjense, ¡oh jóvenes!

(Barítono)

¡Oh, oh, oh,

en mí hoy floreció!

Ya el amor de una doncella todo me encendió.

Amor nuevo, amor nuevo

es el que me hirió.

(Coro de mujeres)

A mí robustece

el prometer,

y me desfallece

no conceder.

(Soprano y niños)

¡Oh, oh, oh,

en mí hoy floreció!

Ya el amor de una doncella

todo me encendió.

Amor nuevo, amor nuevo

es el que me hirió.

(Coro de varones)

En tiempo de bruma,

el hombre en paz;

tibia primavera

lo hace procaz.

(Barítono)

¡Oh, oh, oh

en mí hoy floreció!

Ya el amor de una doncella

todo me incendió.

Amor nuevo, amor nuevo

es el que me hirió.

(Coro de mujeres)

Me convida al juego

mi doncellez,

y me arrastra luego

mi sencillez.

(Soprano y niños)

¡Oh, oh, oh... 
(Chorus)

Veni, domicella, cum gaudio.

Veni, veni, pulchra, jam pereo.

(Barytonus, pueri et chorus)

$\mathrm{O}, \mathrm{o}, \mathrm{o}$, totus floreo!

Jam amore virginali totus ardeo, Novus, novus, novus amor est, quo pereo.

(Soprano. Lentissime)

23. Dulcissime:

totam tibi

subdo me.

\section{BLANZIFLOR ET HELENA}

24. (Chorus)

Ave, formosissima, gemma pretiosa, ave, decus virginum, virgo gloriosa!

Ave, mundi luminar, ave, mundi rosa!

Blanziflor et Helena

Venus generosa!

25. O Fortuna (ut in initio).
(Coro)

Ven, oh, jovencita, y alégrate.

Vente, ven, hermosa, reanímate.

(Barítono, niños y coro)

¡Oh, oh, oh.

en mí hoy floreció!

Ya el amor de una doncella todo me incendió.

Amor nuevo, amor nuevo

es el que me hirió.

(Soprano. Muy lentamente)

23. Dulcísimo:

toda me

sujeto a ti.

\section{BLANZIFLOR Y HELENA}

24. (Coro)

¡Salve, la hermosísima,

la gema preciosa;

salve, prez de vírgenes,

oh virgen gloriosa!

¡Salve, luz del mundo,

del mundo, ave, rosa!

Blanziflor y Helena.

¡Venus generosa!

25. Oh fortuna (como al principio). 


\section{BIBLIOGRAFÍA ${ }^{3}$}

Arias y ARIAS, Ricardo, La poesía de los Goliardos, Madrid, Gredos, 1970.

Carmina Burana, prólogo de Carlos Yarza, texto en latín y traducción al español de Lluís Moles, Barcelona, Seix Barral, 1978.

Carmina Burana, texto en latín y versión al catalán de Joan Petit y prólogo de Antoni Comas, Barcelona, Quaderns Crema, 1991.

CURTIUs, Ernst Robert, Literatura europea y Edad Media latina, México, FCE, 1955. DE VILlENA, Luis Antonio, Dados, amor y clérigos (Los goliardos en la Edad Media europea), Madrid, CUPSA, 1978 (reeditado en Sevilla, Renacimiento, 2010).

La poesía de los goliardos. Carmina Burana (selección de Carlos Montemayor), México, SEP, 1987 (Cien del mundo).

Lírica latina medieval. Tomo I: Poesías profanas, edición bilingüe preparada por J. O. Reta y Manuel A. Marcos Casquero, Madrid, Biblioteca de Autores Cristianos, 1995.

Quirós, Manuel Antonio, La Edad Media, los «Carmina Burana» y Carl Orff, San José (Costa Rica), Editorial Universidad de Costa Rica, 2007.

${ }^{3}$ La bibliografía fue elaborada con el fin de dar a conocer las publicaciones recientes en español sobre el tema [N. del E.]. 
